Article

\title{
Facile Preparation of Graphene Oxide-MIL-101(Fe) Composite for the Efficient Capture of Uranium
}

\author{
Bing Han *, Enyao Zhang and Gong Cheng \\ MOE Key Laboratory of Resources and Environmental Systems Optimization, College of Environmental Science \\ and Engineering, North China Electric Power University, Beijing 102206, China; \\ zhangenyao0516@163.com (E.Z.); cg1182229006@ncepu.edu.cn (G.C.) \\ * Correspondence: hanbing01@ncepu.edu.cn; Tel.: +86-10-6177-1470
}

Received: 11 October 2018; Accepted: 13 November 2018; Published: 16 November 2018

check for updates

\begin{abstract}
Graphene oxide (GO)-MIL-101(Fe) (Fe-based metal-organic frameworks (MOFs) with Fe(III) as the metal anode and 2-aminobenzene-1,4-dicarboxylic acid as a ligand) sandwich composites are designed and fabricated through a facile in situ growth method. By modulating the addition amount of GO nanosheets, composites containing MIL-101(Fe) octahedrons with a tunable dimension and density are achieved. The optimized ratio between individual components is determined through adsorption experiments. Adsorption isotherms reveal an enhanced adsorption efficiency and improved adsorption capacity of GO15-MIL-101(Fe) (GO dosage is $15 \mathrm{mg}$ ) in comparison with raw MIL-101(Fe) nanocrystals. Experimental evidence indicates that the removal of U(VI) by the composite is based on inner-sphere surface complexation and electrostatic interaction. The improved adsorption performance originates from the optimized synergistic effects of GO and MIL-101(Fe) octahedrons. In summary, this work offers a facile synthetic method to achieve cost-effective composites towards the $\mathrm{U}(\mathrm{VI})$ capture. It also lays the foundation for the design of novel adsorbents with the full play of component's functionality.
\end{abstract}

Keywords: graphene oxide; MIL-101(Fe); composite; adsorption; uranium

\section{Introduction}

The severe energy and environmental crisis calls for the development of green energy sources. Nuclear power is an effective solution for this problem as a sustainable energy source with a high efficiency. However, the radioactive contamination from the production process of nuclear energy can cause potential ecological threats and biological toxicity [1-3]. In particular, uranium-contamination is included in the major nuclide pollutants that are urgently required to be eliminated from the polluted waters [4]. The widely used techniques for the removal of uranyl ions consist of solvent extraction [5], ion-exchange [6], and adsorption. In particular, adsorption takes advantages of the rapid and highly efficient treatment of uranium by developing adsorbent materials with programmable functionalization [7]. Until now, much attention has been paid to the development of nanostructured adsorbents for higher adsorption efficiency [8,9]. One of the most promising directions is the fabrication of composite materials which combine the functionality of individual components into one $[10,11]$. The key point lies in the component selection and sophisticated structure design for the optimization of synergistic effect inside the composite materials.

Among the various adsorbents, functional carbon nanomaterials including one dimensional carbon nanofiber/nanotube, two-dimensional graphene oxide (GO) [12,13], and three dimensional functionalized carbon nanostructures take the advantages of a large surface area and easy functionalized capability, which endow them the great potential as novel adsorbents for uranium-based nuclide species [14-18]. Zänker et al. reported that the adsorption of uranyl ions on pristine carbon 
nanotube (CNT) reached $5.0 \mathrm{mmol} \mathrm{g}^{-1}$ at $\mathrm{pH}=5.0$ under $298 \mathrm{~K}$ [19]. Wang et al. demonstrated the good adsorption performance of GO towards $\mathrm{U}(\mathrm{VI})$ in aqueous solution [20]. The tedious and high-cost synthetic procedures of CNT and GO promote the studies on the fabrication of CNT/GO-based composites which maintain a good performance at a lower dosage of CNT and GO by the introduction of other components and optimizing the synergistic effects [21,22]. Compared with CNT, fabrication of GO-based composite materials benefits the adsorption properties in several ways. On the one hand, the expansive surface of GO gives rise to the easy attachment of other nanomaterials, making them excellent substrates. On the other hand, the formation of composites through surface growth method helps overcome the aggregation problem of GO in solutions, which improves the exposure of functional groups. In the past few years, various GO-based composite adsorbents with diverse functionalities have been designed and fabricated, including a magnetic GO composite [23], GO-polymer composite [24,25], GO-layered double hydroxides (LDHs) composite [26], etc.

Metal-organic frameworks (MOFs) are a series of crystalline hybrids based on the bridging network between metal ions and organic ligand molecules [27]. Owing to their high surface area, tunable porous structure, and versatile chemical functionality, MOFs have become high-profile candidates in application fields of catalysis [28], adsorption [29-32], and membrane formation [33]. Very recently, MOFs have found new opportunities in the removal of uranyl ions [34,35]. MIL-101, as a series of MOFs with different metal centers ( $\mathrm{Al}, \mathrm{Cr}$, and $\mathrm{Fe}$ ), has received much attention in the recovery of uranium polluted waters due to its chemical stability in acid solutions [36-38]. Compared with pristine materials, functionalized MOFs have shown optimized adsorption performance with enriched binding sites [39]. The post-synthetic strategy is the commonly used method to introduce functional groups on the MIL-101 host. However, the multistep post-grafting process is time-consuming and usually involves polluting acid such as $\mathrm{HNO}_{3}$ [40]. One step or the in situ fabrication of MOF-based composite is a more facile and environmentally benign synthetic method to achieve novel adsorbents with a satisfying performance. Several previous studies have provided excellent examples for GO-MOF composites as adsorbents [41,42].

Herein, we presented the fabrication of the GO-MIL-101(Fe) composite through in situ growth method. Different ratio of GO and MIL-101(Fe) in the composite was tuned through changing the addition amount of GO nanosheets. The size and distribution density of MOF polyhedrons varied due to the interference of the functional groups on GO nanosheets towards the nucleation and growth of MIL-101 seed. Morphology imaging based on scanning electron microscopy (SEM) and a composition analysis from powder X-ray diffraction (XRD), Attenuated total internal reflection Fourier (ATR-FTIR) and X-ray photoelectron spectroscopy (XPS) measurements eVidenced the successful synthesis of the composite material. Batch adsorption experiments further confirmed the much better adsorption performance of the GO15-MIL-101(Fe) composite than pristine MIL-101(Fe) with larger $\mathrm{U}(\mathrm{VI})$ adsorption capacity and superior reusing ability. Mechanism analysis further illustrated the importance of optimizing synergistic effects between individual components in improving the adsorption performance. This work would benefit the design and development of composite adsorbents with a versatile functionalization for the potential application in the effective recovery of $\mathrm{U}(\mathrm{VI})$ pollution.

\section{Materials and Methods}

\subsection{Chemicals}

Graphite (CP grade, $\leq 300$ mesh) was purchased from Sinopharm Chemical Regent, Beijing, China. Iron(III) chloride hexahydrate $\left(\mathrm{FeCl}_{3} \cdot 6 \mathrm{H}_{2} \mathrm{O}, 97 \mathrm{wt} \%\right)$, 2-aminobenzene-1,4-dicarboxylic acid $\left(\mathrm{NH}_{2}-\mathrm{H}_{2} \mathrm{BDC}, 98 \mathrm{wt} \%\right)$, and $\mathrm{N}, \mathrm{N}$-dimethylformamide (DMF, $99.8 \mathrm{wt} \%$ ) were provided by Alfa Aesar, Shanghai, China. Polyvinylpyrrolidone (PVP, $\mathrm{Mw}=30,000)$ was provided by Xilong Scientific Co., Ltd., Shanghai, China. Uranyl nitrate was obtained from Sigma Aldrich, Beijing, China. The graphene oxide (GO) was synthesized based on the Hummers method [43]. 


\subsection{Characterization}

The dimension and morphology of all the samples were obtained from scanning electron microscopy (SEM) (Hitachi S4800, Tokyo, Japan). X-ray diffraction (XRD) D/max-TTRIII (Rigaku, Tokyo, Japan) was used to provide the crystalline information of the samples. Attenuated total internal reflection Fourier (ATR-FTIR) spectra were obtained on a Bruker TENSOR-27 (Bruker Optics, Bremen, Germany). The surface composition and binding state information were achieved from X-ray photoelectron spectroscopy (XPS) (Thermo Escalab 250Xi, Waltham, MA, USA). Pore information and specific surface area were analyzed by a Micromeritics ASAP 2010 (Norcross, GA, USA). $\zeta$ potential data were collected from a Zetasizer Nano ZS (Malvern Instrument, Worcestershire, UK). For measuring the zeta potential, the $\mathrm{pH}$ values of the achieved samples $\left(c_{\mathrm{NaCl}}=10 \mathrm{mM}\right)$ were adjusted to values between 1 and 11 by adding $\mathrm{HCl}$ or $\mathrm{NaOH}$, respectively.

\subsection{Fabrication of the GO-MIL-101(Fe) Composite with Different GO Contents}

GO-MIL-101(Fe) was synthesized with an in situ growth method. In a typical procedure, $10 \mathrm{mg}$, $15 \mathrm{mg}, 18 \mathrm{mg}, 20 \mathrm{mg}$ of $\mathrm{GO}$ and $54.1 \mathrm{mg}$ of $\mathrm{FeCl}_{3} \cdot 6 \mathrm{H}_{2} \mathrm{O}(0.2 \mathrm{mmol})$ were dispersed in $6 \mathrm{~mL}$ DMF and formed solution $\mathrm{A}, 18.2 \mathrm{mg} \mathrm{NH}-\mathrm{H}_{2} \mathrm{BDC}(0.1 \mathrm{mmol})$ and $4 \mathrm{mg}$ PVP were dissolved in $6 \mathrm{~mL}$ DMF to form solution B. Subsequently, solutions A and B were placed in a microwave vessel and sealed. After reaction at $160{ }^{\circ} \mathrm{C}$ for $10 \mathrm{~min}$, the solid products were collected by centrifugation at $5000 \mathrm{rpm}$ for $10 \mathrm{~min}$. The samples were washed twice with DMF followed by washing with ethanol two times to remove residual DMF. Finally, the product was dried in vacuum overnight for further use. The achieved composite was denoted as GO10(15, 18, 20)-MIL-101(Fe). MIL-101(Fe) materials were fabricated according to the above method without the addition of GO. The mass ratio of GO and MIL-101(Fe) was calculated to be 1:7.42 by measuring the mass of both GO15-MIL(101) and the original added GO.

\subsection{Batch Sorption Experiments}

The adsorption properties of composite samples were studied by batch experiments. Stock dispersions of adsorbents including MIL-101(Fe) and the GO10(15, 18, 20)-MIL-101(Fe) composites were prepared with a concentration of $1.2 \mathrm{~g} \mathrm{~L}^{-1}$. U (VI) stock solution $\left(0.2 \mathrm{~g} \mathrm{~L}^{-1}\right)$ was also prepared. Adsorption suspensions to perform adsorption experiment with different conditions were prepared by diluting the stock adsorbent suspension and $\mathrm{U}(\mathrm{VI})$ solution with distilled water. The adsorbent concentration in the adsorption suspension was $0.20 \mathrm{~g} \mathrm{~L}^{-1}$ except for the adsorption experiment with different adsorbent doses. The initial $\mathrm{U}$ concentration of $10 \mathrm{mg} \mathrm{L}^{-1}$ is selected to study the adsorption behavior of the GO-Fe MOF composite towards $\mathrm{U}(\mathrm{VI})$, which simulated the example of industrial effluents with a relatively high $\mathrm{U}$ concentration. The effect of $\mathrm{pH}$ on the adsorption efficiency was investigated by tuning the solution $\mathrm{pH}$ with a different concentration of $\mathrm{HNO}_{3}$ or $\mathrm{NaOH}(0.01 \mathrm{mM} 0.1 \mathrm{M})$, which guaranteed that the added amount of $\mathrm{HNO}_{3}$ or $\mathrm{NaOH}$ was almost negligible in comparison with the volume of the adsorption solution. The $\mathrm{pH}$ modulation process was monitored by a $\mathrm{pH}$ meter. The adsorption efficiency of GO15-MIL-101(Fe) under different initial $\mathrm{U}$ concentrations $\left(0.035 \mathrm{mg} \mathrm{L}^{-1}, 1.3 \mathrm{mg} \mathrm{L}^{-1}, 3 \mathrm{mg} \mathrm{L}^{-1}\right)$ was also tested $(\mathrm{pH}=5.5, \mathrm{~T}=298 \mathrm{~K})$. These concentrations took reference from a previous study [6]. The adsorption isotherms were achieved by performing adsorption experiment under different initial $\mathrm{U}(\mathrm{VI})$ concentrations $\left(5 \mathrm{mg} \mathrm{L}^{-1} \sim 70 \mathrm{mg} \mathrm{L}^{-1}\right.$ with $5 \mathrm{mg} \mathrm{L}^{-1}$ intervals) under $\mathrm{pH}=5.5$ at different temperatures $(298 \mathrm{~K}, 313 \mathrm{~K}, 328 \mathrm{~K})$. The $\mathrm{pH}$ of the adsorption suspensions was tuned to 5.5 at $298 \mathrm{~K}$ and then the adsorption solutions were placed in a shaker under different temperatures. Adsorption kinetics were performed at ambient temperature $(\mathrm{pH}=5.5)$. The influence of coexisting ions (cations from $\mathrm{NaNO}_{3}, \mathrm{KNO}_{3}, \mathrm{Mg}\left(\mathrm{NO}_{3}\right)_{2}, \mathrm{Ca}\left(\mathrm{NO}_{3}\right)_{2}$ and anions from $\mathrm{NaNO}_{3}, \mathrm{NaCl}, \mathrm{Na}\left(\mathrm{SO}_{4}\right)_{2}$, and $\mathrm{Na}\left(\mathrm{CO}_{3}\right)_{2}$, the concentration was $0.01 \mathrm{M}$ ) towards the adsorption performance was further investigated. Particularly, the removal efficiency of U(VI) on GO15-MIL-101(Fe) and MIL-101(Fe) was compared in simulated surface water and groundwater. 
The $\mathrm{pH}$, composition, and related ion concentrations were determined based on previous studies (Table S1) [44]. The suspension was agitated for over $24 \mathrm{~h}$ to achieve equilibrium. The concentration of uranyl ions under equilibrium was confirmed by the Arsenazo III based colorimetric method. U (VI) can form a binary complex with Arsenazo III. The uranyl ion content was determined by measuring the absorbance of the complex at $656 \mathrm{~nm}$. Samples with U(VI) concentration in ppb level were tested via inductively coupled plasma optical emission spectrometry (ICP-OES) analysis. The adsorption percentage (Adsorption, \%) and adsorption capacity $\left(q_{e}, \mathrm{mg} \mathrm{g}^{-1}\right)$ can be obtained based on the following equations:

$$
\begin{gathered}
\text { Adsorption }=\frac{\left(C_{0}-C_{e}\right)}{C_{0}} \times 100 \% \\
q_{e}=\frac{\left(C_{0}-C_{e}\right) \times V}{m}
\end{gathered}
$$

where, $C_{0}\left(\mathrm{mg} \mathrm{L}^{-1}\right)$ and $C_{e}\left(\mathrm{mg} \mathrm{L}^{-1}\right)$ correspond to the $\mathrm{U}(\mathrm{VI})$ concentration of the adsorption suspension at the beginning and equilibrium, respectively. $V(\mathrm{~mL})$ and $m(\mathrm{~g})$ are the solution volume and adsorbent dosage, respectively. Triplicate measurements showed that the relative errors were within $5 \%$.

\subsection{Desorption and Reusing Studies}

The reusing ability of the GO15-MIL-101(Fe) was studied through monitoring the adsorption efficiency of the 8-cycles regenerated samples. $\mathrm{U}(\mathrm{VI})$ was desorbed from the sample through the washing process of $0.1 \mathrm{M} \mathrm{HNO}_{3}$. The as regenerated sample was centrifuged and washed with deionized water for the removal of acid. Then the dried powder was used in the next adsorption process. The $\mathrm{U}$ containing $\mathrm{HNO}_{3}$ wastewater was collected by a professional liquid waste treatment plant or stored to be reused as raw pollutant water in further $\mathrm{U}$ removal research.

\section{Results and Discussion}

\subsection{Characterization of GO-MIL-101(Fe) Composite}

As shown in Figure 1a, pure GO presented a two-dimensional morphology with lateral size up to tens of micrometers. GO-MIL-101(Fe) composites were fabricated through a facile one-pot in situ growth method. The component ratio was adjusted by tuning the addition amount of GO in the synthetic precursor solution. Figure $1 \mathrm{~b}-\mathrm{d}$ confirmed the successful growth of nanosized MIL-101(Fe) octahedrons on GO nanosheets. The negligible dispersed MIL-101(Fe) indicated that most MIL-101(Fe) nanoparticles formed on the GO matrix. Moreover, MIL-101 octahedrons were well distributed on both sides of the GO nanoplatelets, which guaranteed the synergistic interaction between individual compositions. Notably, the dimension of MIL-101(Fe) octahedrons in the composite decreased with the amount of GO increasing (460 nm for GO10-MIL-101(Fe), $350 \mathrm{~nm}$ for GO15-MIL-101(Fe), and $150 \mathrm{~nm}$ for GO20-MIL-101(Fe)). It was reported that low concentrations of a monocarboxylic acid with different $\mathrm{pKa}$ values (1.60 10.15) could modulate the crystal growth of MIL-101(Cr), with higher pKa leading to smaller nanoparticles [45]. GO synthesized from Hummers method possessed many oxygenated groups like carboxylic $(\mathrm{pKa}=4.3$ and 6.6) and phenolic groups $(\mathrm{pKa}=9.8)$ [46]. Therefore, both carboxylic groups and phenolic groups gave rise to the controlling of the size of MIL-101 in GO15-MIL-101(Fe) composite. Considering that most MIL-101 octahedrons nucleated on the surface of GO, phenolic groups with especially high pKa played a dominant role. We postulated that GO interfered with the nucleation of MIL-101(Fe) which led to smaller sized nanoparticles with the addition amount of GO increasing.

As shown in Figure S1, all the XRD patterns of the composite materials showed peaks at $2 \theta=5.88^{\circ}$ and $9.08^{\circ}$, which can be assigned to typical (531), (911) diffractions of MIL-101(Fe), confirming the successful synthesis of the composite sample $[47,48]$. However, the decreased peak intensity in GO20-MIL-101(Fe) indicated the reduction of MOF crystallinity, which was also reflected from the loss 
of the octahedron morphology. ATR-FTIR spectroscopy was used to identify the functional groups of the GO-MIL-101(Fe) composite. The broad band in the range of $3000 \mathrm{~cm}^{-1} \sim 3500 \mathrm{~cm}^{-1}$ originated from the hydroxyl groups of absorbed water molecules. The IR signals at $3475 \mathrm{~cm}^{-1}$ and $3345 \mathrm{~cm}^{-1}$ in Figure $2 \mathrm{a}$ corresponded to the asymmetric and symmetric $\mathrm{N}-\mathrm{H}$ stretching vibrations in amino groups of MIL-101(Fe) [49]. Because of the low concentration of MIL-101(Fe) in the composite, these peaks became negligible in Figure 2b,c. For the sample MIL-101, FT-IR signals at $1575 \mathrm{~cm}^{-1}$ and $1429 \mathrm{~cm}^{-1}$ were asymmetric and symmetric stretching of carboxylic groups in the organic ligand $\mathrm{NH}_{2} \mathrm{BDC}$, respectively $[50,51]$. The peak at $\sim 1379 \mathrm{~cm}^{-1}$ obviously indicated the effect of the amino groups on the symmetric stretching of carboxylic groups. $\mathrm{C}-\mathrm{N}$-stretching vibrations were clearly recognized at $1257 \mathrm{~cm}^{-1}$ in IR spectrum of MIL-101(Fe) [40]. The spectrum peaks at $1501 \mathrm{~cm}^{-1}$ and $767 \mathrm{~cm}^{-1}$ can be attributed to the stretching vibration $(\mathrm{C}=\mathrm{C})$ and deformation vibration $(\mathrm{C}-\mathrm{H})$ of benzene, respectively [52]. As shown in Figure 2b, the asymmetric stretching of $\mathrm{O}=\mathrm{C}-\mathrm{O}, \mathrm{C}-\mathrm{N}$ stretching, and $\mathrm{C}-\mathrm{H}$ deformation vibration were suppressed, which was more obvious with the GO increasing. This result implied the modulation of GO towards the growth of MIL-101(Fe). The comparison of FTIR spectra between GO15-MIL-101(Fe) and that loaded with uranyl ions can be used to deduce the uranyl ions-composite interaction. As shown in Figure 2c, the peak at $\sim 920 \mathrm{~cm}^{-1}$ can be assigned to the stretching vibration of the linear structure of the $\mathrm{UO}_{2}{ }^{2+}$ group in the $\mathrm{U}(\mathrm{VI})$-loaded materials [53].
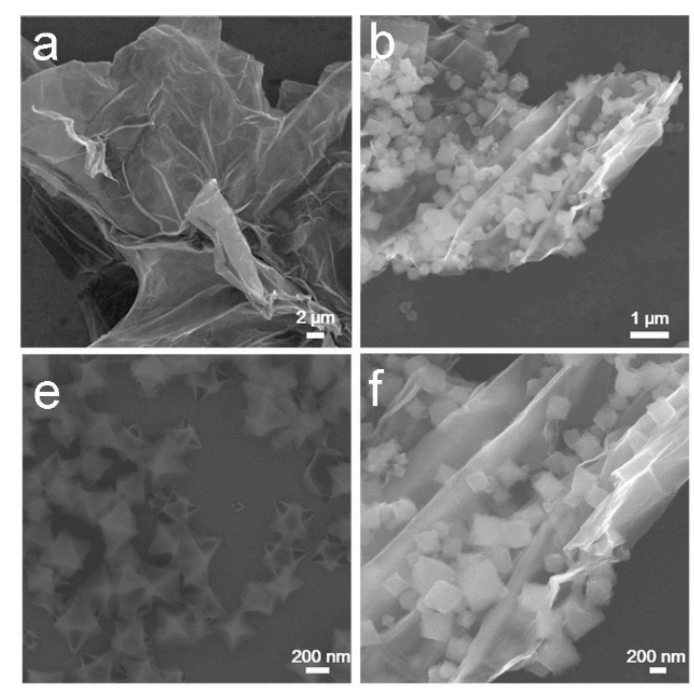
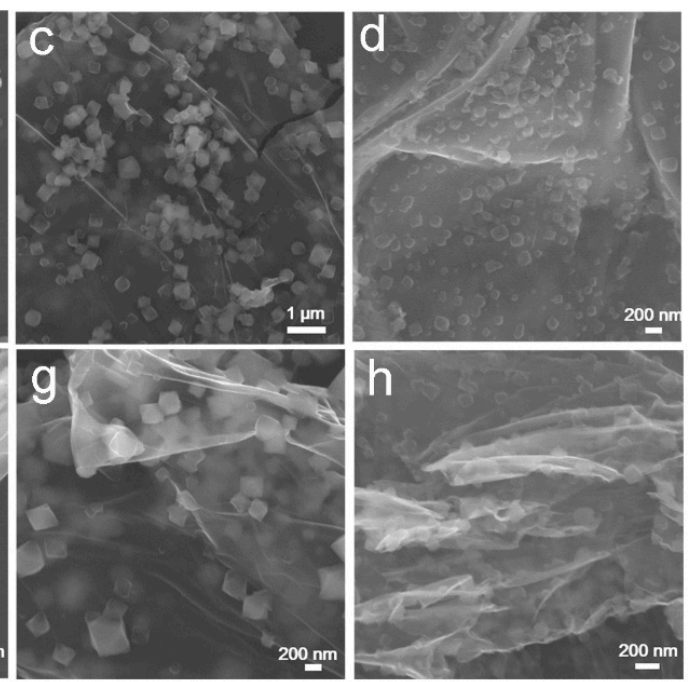

Figure 1. The scanning electron microscopy (SEM) images of (a) GO, (b,f) GO10-MIL-101(Fe) composite, (c,g) GO15-MIL-101(Fe) composite, (d,h) GO20-MIL-101(Fe) composite and (e) MIL-101(Fe).

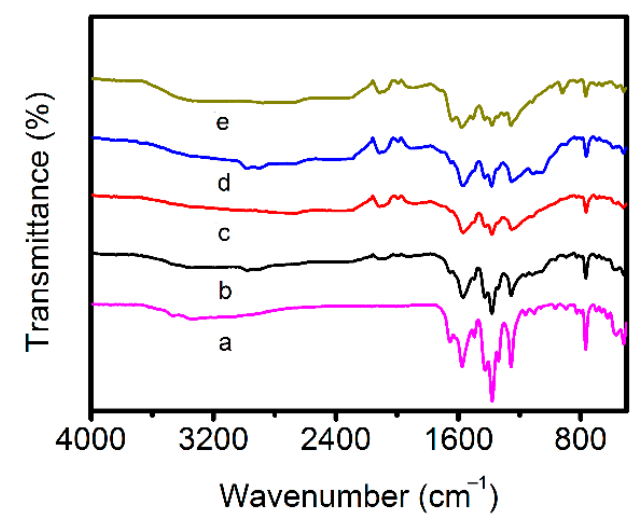

Figure 2. The Attenuated total internal reflection Fourier (ATR-FTIR) spectra of (a) MIL-101(Fe), (b) GO10-MIL-101(Fe), (c) GO15-MIL-101(Fe), (d) GO20-MIL-101(Fe) and (e) GO-15-MIL-101(Fe) loaded with U(VI). 
The XPS measurement provided the information of elemental composition and surface binding condition of GO-MIL-101(Fe) composite. XPS survey spectra showed the typical peaks of Fe2p, C1s, O1s, and N1s in GO-MIL-101(Fe) composites and additional U4f peaks upon the uptake of uranyl ions (Figure 3a). The O auger signal $(976 \mathrm{eV})$ was observed [54]. The Fe auger signals $(893 \mathrm{eV}, 841 \mathrm{eV}$, and $786 \mathrm{eV})$ and $\mathrm{U}_{4 \mathrm{~d}_{5 / 2}}$ signal $(740 \mathrm{eV})[55,56]$ were also recognized. XPS signals at $311 \mathrm{eV}$ and $554.9 \mathrm{eV}$ can be assigned to the $\mathrm{C} 1 \mathrm{~s}$ and O1s satellite peaks [57-59]. The negligible observation of the characteristic signal of DMF molecules (C-N symmetric stretching at $866 \mathrm{~cm}^{-1}$ and the $\mathrm{O}=\mathrm{C}-\mathrm{N}$ stretching mode at $659 \mathrm{~cm}^{-1}$ ) indicated the removal of residual DMF molecules in the system. The $\mathrm{C} 1 \mathrm{~s}$ spectra of the composite materials can be deconvoluted into three peaks including $\mathrm{C}-\mathrm{C}, \mathrm{C}-\mathrm{O}$, and $\mathrm{C}=\mathrm{O}$ with the binding energy increasing. $\mathrm{O} 1 \mathrm{~s}$ spectra were composed of oxygen anion $\left(\mathrm{OH}^{-1}\right)$ at $530.9 \mathrm{eV}, \mathrm{C}=\mathrm{O}$ (carboxylic group) at $531.5 \mathrm{eV}$ and $\mathrm{C}-\mathrm{O}$ in aromatic rings, phenols, and ethers at $533.4 \mathrm{eV}$ [60]. The analysis of the XPS data for GO-MIL-101(Fe) samples before and after the uranyl ions adsorption demonstrated the interaction between the adsorbents and $\mathrm{U}(\mathrm{VI})$. As shown in Figure $3 \mathrm{~b}$, GO-MIL-101(Fe)-U(VI) exhibited typical U4f XPS peak which consisted of two doublet-peaks at $382 \mathrm{eV}$ $\left(\mathrm{U}_{4} \mathrm{f}_{7 / 2}\right)$ and $392 \mathrm{eV}\left(\mathrm{U}_{4 f_{5 / 2}}\right)$ [6]. The peak at $399.97 \mathrm{eV}$ and $403.13 \mathrm{eV}$ corresponded to the N1s XPS signal with the former corresponding to the amine groups on MIL-101(Fe) and the latter peak indicated the presence of $\mathrm{N}$ doping in the form of pyridinic $\mathrm{N}$-oxide on $\mathrm{GO}$. Such $\mathrm{N}$ doping may originate from the DMF treatment under the solvothermal condition [61]. The decreased intensity of the N1s peak in GO-MIL-101(Fe)-U in comparison with the raw sample indicated that the amino group of $\mathrm{NH}_{2} \mathrm{BDC}$ ligand contributed partial adsorption performance. The decreased intensity of $\mathrm{C}-\mathrm{O}$ and $\mathrm{C}=\mathrm{O}$ peaks of $\mathrm{C} 1 \mathrm{~s}$ as well as the decreased area of $\mathrm{O} 1 \mathrm{~s}$ peaks indicated the interaction between the uranyl ions and different sort of functionalized oxygen groups on the composite. The XPS analysis eVidenced the synergistic effect of GO and MIL-101(Fe) in the removal of $\mathrm{U}(\mathrm{VI})$, which agrees well with the FT-IR results.

Brunauer-Emmett-Teller (BET) analysis further provided the surface area and pore structure information. MIL-101(Fe) showed a mixture of type I and IV adsorption-desorption isotherms with the sharp $\mathrm{N}_{2}$ uptakes at low relative pressure $\left(\mathrm{P} / \mathrm{P}_{0}<0.1\right)$, indicating its micro/mesoporous structure (Figure S2a) [62]. The pore size distribution result (Figure S2b) indicated the existence of $2.15 \mathrm{~nm}$ and $2.52 \mathrm{~nm}$ mesocages and $1.26 \mathrm{~nm}$ microcages in MIL-101(Fe). In contrast, GO-15-MIL-101(Fe) also exhibited characteristics of type II isotherms, which revealed that the introduction of macropores in the composite (Figure S2c). The $\mathrm{H}_{3}$-type hysteresis loops implied that the sandwich structures formed in the 2-D GO nanosheets-MIL-101 octahedrons composite gave rise to slit mesopores [47,63]. Figure S2d further showed enlarged mesocages of $\sim 2.75 \mathrm{~nm}$. Both isotherm observation and statistic data (Table S2) showed that GO15-MIL-101(Fe) had a lower specific surface area and larger total pore volume than that of pure MIL-101(Fe), which resulted from the formation of meso-macropores in the composite structure. The pore texture analysis illustrated that the GO15-MIL-101(Fe) composite synthesized from the in situ growth method may modulate the pore structure of both individual components, which may optimize the adsorption performance. 

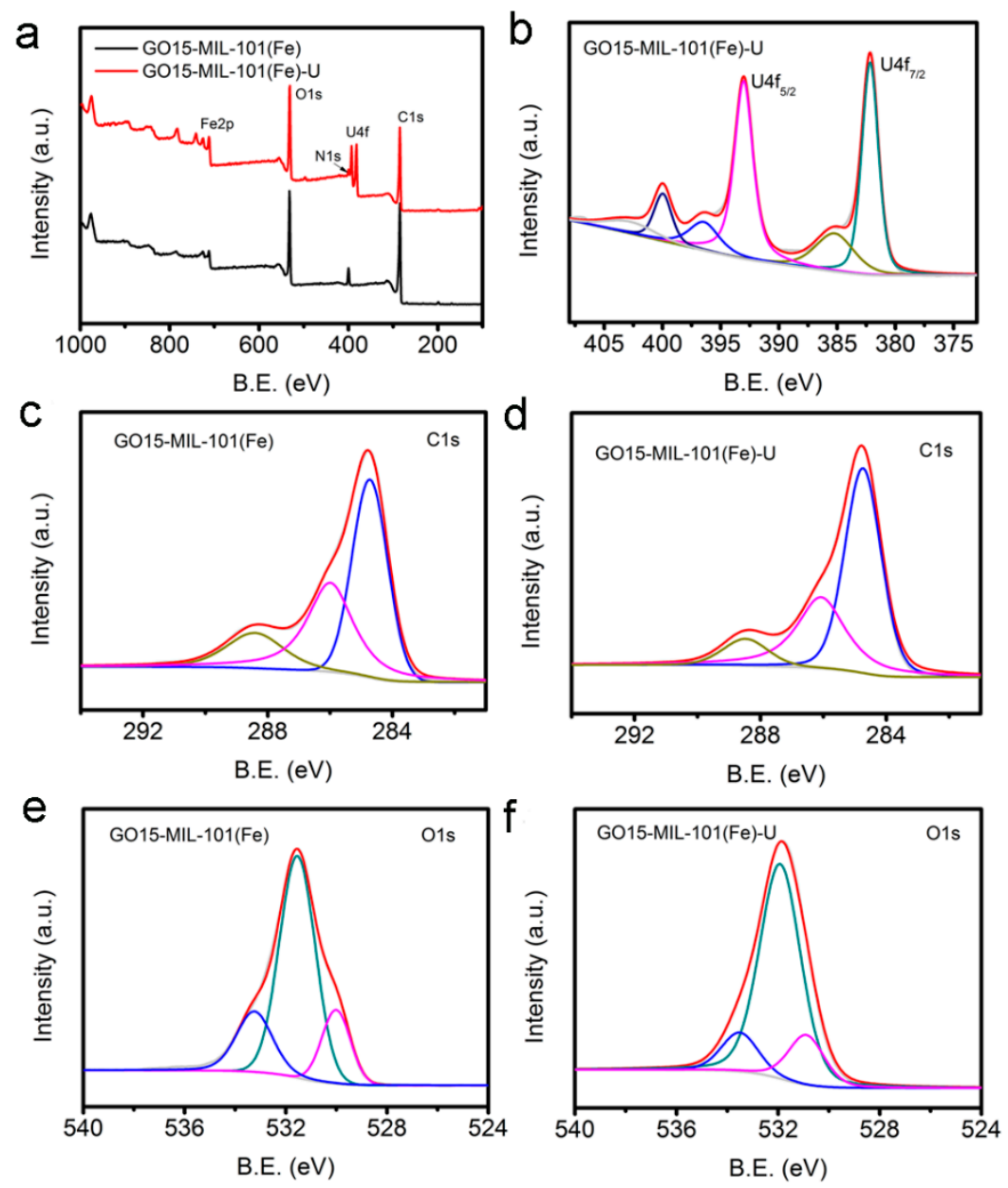

Figure 3. (a) The survey spectra obtained from X-ray photoelectron spectroscopy (XPS) of GO15-MIL-101(Fe) before and after the adsorption of U(VI), high-resolution spectra of U4f for (b) GO15-MIL-101(Fe)-U, C1s for (c) GO15-MIL-101(Fe) and (d) GO15-MIL-101(Fe)-U, O1s for (e) GO15-MIL-101(Fe) and (f) GO15-MIL-101(Fe)-U.

\subsection{U(VI) Adsorption on the GO-MIL-101(Fe)}

Figure 4a showed the change of the adsorption efficiency of MIL-101(Fe) and GO-MIL-101(Fe) towards $\mathrm{U}(\mathrm{VI})$ as a function of $\mathrm{pH}$. With $\mathrm{pH}$ varies ranging from 2.0 to 11.0, the adsorption percentage of uranyl ions increased slowly firstly (Stage I), followed by a rapid improvement (Stage II) and then it was maintained at a high level (Stage III). GO-MIL-101(Fe) composite materials exhibited decreased adsorption efficiency after Stage III. However, the $\mathrm{pH}$ turning point of Stage I-II and Stage II-III is different for MOF and GO-MOF composites. Pure MIL-101(Fe) and GO10-MIL-101(Fe) ended stage I at $\mathrm{pH}=4$, while that for GO15-MIL-101(Fe) and GO20-MIL-101(Fe) is $\mathrm{pH}=3$. Furthermore, pure MIL-101(Fe) begins stage III at $\mathrm{pH}>$ 7.4. In comparison, GO-MIL-101(Fe) composite reached high level of adsorption efficiency at lower $\mathrm{pH}$ (GO10-MIL-101(Fe)/92.2\% at $\mathrm{pH}=7, \mathrm{GO} 15-\mathrm{MIL}-101$ (Fe)/98.1\% at $\mathrm{pH}=6.5, \mathrm{GO} 20-\mathrm{MIL}-101(\mathrm{Fe}) / 96.7 \%$ at $\mathrm{pH}=7)$. Considering the complexity of contaminated water sources, the adsorption efficiency of GO15-MIL-101(Fe) was tested with different initial U concentrations. Under initial $\mathrm{U}(\mathrm{VI})$ concentration of $0.035 \mathrm{mg} \mathrm{L}^{-1}, 1.3 \mathrm{mg} \mathrm{L}^{-1}$ and $3 \mathrm{mg} \mathrm{L}^{-1}$, the adsorption percentage was $40 \%, 93.1 \%$, and $99.6 \%$ with $21 \mu \mathrm{g} \mathrm{L}^{-1}, 89 \mu \mathrm{g} \mathrm{L}-1$, and $12 \mu \mathrm{g} \mathrm{L}^{-1}$ $\mathrm{U}(\mathrm{VI})$ left in water (Figure S3), respectively. The lowered adsorption percentage at $\mathrm{U}(\mathrm{VI})$ concentration of $0.035 \mathrm{mg} \mathrm{L}^{-1}$ may originate from the reduced driving force. The final $\mathrm{U}$ concentration upon treatment of contaminated waters with $\mathrm{C}_{0}=0.035 \mathrm{mg} \mathrm{L}^{-1}$ and $3 \mathrm{mg} \mathrm{L}^{-1}$ by GO-MIL-101(Fe) can reach the requirement of the Chinese National Emission Standard $\left(0.05 \mathrm{mg} \mathrm{L}^{-1}\right)$ for discharged water and 
the US Environmental Protection Agency (EPA) $\left(0.03 \mathrm{mg} \mathrm{L}^{-1}\right)$ for potable water. This result indicated that application potential of as-prepared composite samples in the treatment of $U$ contaminated water in a specific concentration range. Due to the highest adsorption percentage in the whole $\mathrm{pH}$ range, GO-15 MIL-101(Fe) was selected as the model sorbent for further adsorption experiments. Moreover, the deprotonating condition of surface functional groups can greatly affect the performance of adsorbents. Figure $4 \mathrm{~b}$ displayed the surface charge information of the GO-MIL-101(Fe) composites and pure MIL-101(Fe). All the samples showed a decreasing trend from positive charges with $\mathrm{pH}$ value increased in the range of 2.0-11.0. The positive zeta potential originated from protonation of amine group in the organic linker of MIL-101(Fe), which were the dominant components of the composite samples. Compared with pure MIL-101(Fe), the composite samples had a lower zeta potential due to the introduction of GO. At each pH, GO15-MIL-101(Fe) exhibited the most negative zeta potential. The isoelectric point of GO-15MIL-101(Fe) appeared at the lowest $\mathrm{pH}$. The zeta potential result of as-prepared samples agreed well with the effect of $\mathrm{pH}$ on the adsorption efficiency of the samples towards U(VI). For GO15-MIL-101(Fe), the surface negative charging greatly improved with the dissociation of oxygenated groups on GO nanosheets in the $\mathrm{pH}$ range of 3.0-7.0, which favored the adsorption of $\mathrm{U}(\mathrm{VI})$ cations. As shown in Figure S4, negative charged $\mathrm{UO}_{2}(\mathrm{OH})_{4}{ }^{2-}$ would dominate in aqueous solution with $\mathrm{pH}>9.0$ [17]. The repulsion between the $\mathrm{UO}_{2}(\mathrm{OH})_{4}{ }^{2-}$ species and the composite gave rise to the decreased adsorption efficiency at high $\mathrm{pH}$ value. The change of adsorption percentage with $\mathrm{pH}$ indicated the importance of the electrostatic interaction in the uptake of U(VI) on the composite. Considering the dispersibility of the composite and adsorption performance of adsorbents as well as the interference of complex hydrolysis product such as $\mathrm{UO}_{2}(\mathrm{OH})_{2}$ precipitate at higher $\mathrm{pH}$, a $\mathrm{pH}$ of 5.5 was used as the condition for the adsorption experiments. Furthermore, both samples presented improved adsorption efficiency towards U(VI) with the adsorbent dosage increasing (Figure 4c). The increasing trend can be attributed to increased adsorption sites introduced as the addition amount of adsorbents become larger. Further increasing the adsorbent dosage to $1 \mathrm{~g}$ $\mathrm{L}^{-1}$ gives rise to an adsorption percentage of $96 \%$. Satisfying the treatment result can be achieved either by increasing the adsorbent addition or the adsorption steps. On the other hand, the dependence of adsorption performance on the ionic strength was investigated to eValuate the application potential of adsorbents. It is shown in Figure $4 \mathrm{~d}$ that the amount of $\mathrm{U}(\mathrm{VI})$ adsorbed on GO-15MIL-101(Fe) fluctuated slightly in the range of $\pm 5 \%$ as the concentration of $\mathrm{NaNO}_{3}$ increased, while that of pure MIL-101(Fe) showed an overall decreasing trend. Therefore, the uptake of U(VI) on GO-15MIL-101(Fe) is controlled by inner-sphere surface complexation $[8,64]$.

To eValuate the removal rate of uranyl ions on the MIL-101(Fe) and composite samples, the adsorption percentage of U(VI) under different times was monitored. Figure 4e showed that both GO-15-MIL-101(Fe) and MIL-101(Fe) exhibited a rapid increasing adsorption percentage of U(VI) in the first $30 \mathrm{~min}$ and achieved it in $60 \mathrm{~min}$. In comparison with the composite sample, the adsorption efficiency of MIL-101(Fe) had much lower equilibrium adsorption efficiency $(\sim 26 \%)$. In order to further understand the adsorption process, the adsorption kinetics were simulated by a pseudo-first-order (Equation (3)) [65] and the pseudo-second-order models (Equation (4)) [66]:

Pseudo-first-order model:

$$
\ln \left(q_{e}-q_{t}\right)=\ln q_{e}-k_{1} t
$$

Pseudo-second-order model:

$$
\frac{t}{q_{t}}=\frac{1}{k_{2} q_{e}^{2}}+\frac{t}{q_{e}}
$$

In Equations (3) and (4), $q_{t}$ and $q_{e}$ are the adsorption amount at time $t$ and equilibrium, respectively. $k_{1}$ and $k_{2}$ correspond to the rate constants for the pseudo-first-order model and pseudo-second-order model, respectively. The kinetic plots of uranyl ions on both MIL-101(Fe) and the composite sample can be better fitted by the pseudo-second-order model with the correlation coefficients $\left(R^{2}\right)$ close to 1 (Table 1). This was also confirmed by the almost linear plots of $t / q_{t}$ as a function of $t$ (Figure $4 \mathrm{f}$ ). Therefore, chemisorption is one of the rate-limiting processes in the adsorption kinetics of $\mathrm{U}(\mathrm{VI})$ on 
GO-15-MIL-101(Fe). Moreover, the diffusion of U(VI) onto the surface of adsorbent also affected the adsorption kinetics. The more rapid adsorption performance of GO15-MIL-101(Fe) in comparison with MIL-101(Fe) may arise from the meso-macroporous structure and enlarged mesopore distribution, which served as an efficient ion diffusion channel.
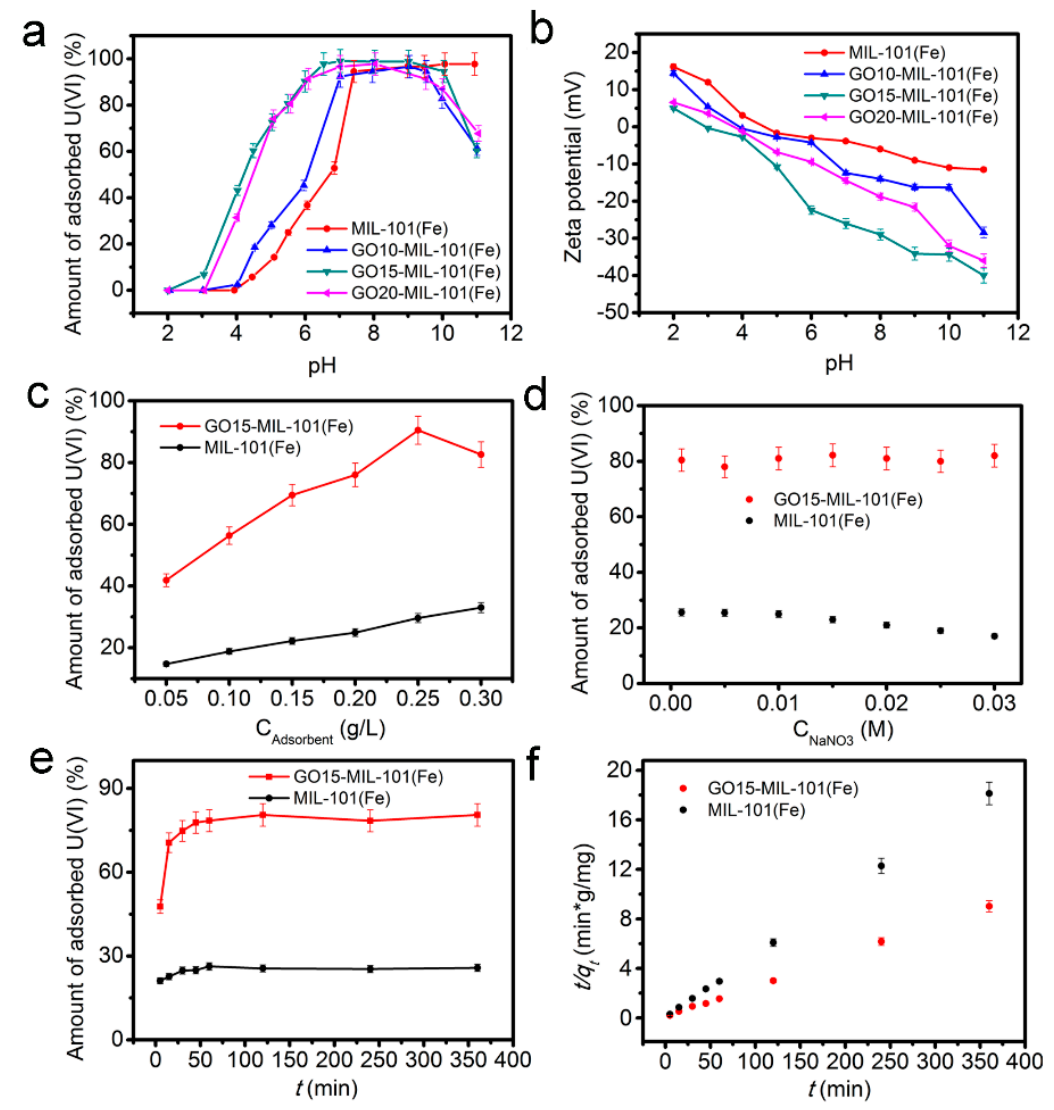

Figure 4. (a) The adsorption efficiency of the MIL-101(Fe) and GO-MIL-101(Fe) composite towards $\mathrm{U}(\mathrm{VI})$ as a function of $\mathrm{pH}\left(C_{0}=10 \mathrm{mg} \mathrm{L}^{-1}, \mathrm{~T}=298 \mathrm{~K}, m / V=0.2 \mathrm{~g} \mathrm{~L}^{-1}\right.$, and $\left.\mathrm{I}_{\mathrm{NaNO}_{3}}=0.01 \mathrm{M}\right)$, (b) the effect of $\mathrm{pH}$ on the zeta potential of the GO10 $(15,20)-\mathrm{MIL}-101(\mathrm{Fe})$ composite and MIL-101(Fe), the effect of (c) adsorbent dose and (d) ionic strength on the adsorption efficiency of MIL-101(Fe) and GO15-MIL-101(Fe) composites. (e) The amount of uranyl ions adsorbed on MIL-101(Fe) and GO15-MIL-101(Fe) composites under different contact times. The experimental condition is $C_{0}=10 \mathrm{mg} \mathrm{L}^{-1}, \mathrm{pH}=5.5, \mathrm{~T}=298 \mathrm{~K}, m / V=0.2 \mathrm{~g} \mathrm{~L}^{-1}$, and $\mathrm{I}_{\mathrm{NaNO}_{3}}=0.01 \mathrm{M}$ for $(\mathbf{b}-\mathbf{e})$. (f) pseudo-second-order simulation result for the adsorption of the U(VI) on MIL-101(Fe) and GO15-MIL-101(Fe) composites.

Table 1. The kinetic parameters for U(VI) adsorption on MIL-101(Fe) and GO15-MIL-101(Fe).

\begin{tabular}{|c|c|c|c|c|c|c|}
\hline \multirow{2}{*}{$\mathrm{C}_{0}\left(\mathrm{mg} \mathrm{L}^{-1}\right)$} & \multicolumn{3}{|c|}{ Pseudo-First-Order } & \multicolumn{3}{|c|}{ Pseudo-Second-Order } \\
\hline & $k_{1}\left(\min ^{-1}\right)$ & $q_{e}\left(\mathrm{mg} \mathrm{g}^{-1}\right)$ & $R^{2}$ & $k_{2}\left(\mathrm{~g} \mathrm{mg}^{-1} \min ^{-1}\right)$ & $q_{e}\left(\mathrm{mg} \mathrm{g}^{-1}\right)$ & $R^{2}$ \\
\hline MIL-101(Fe) & 0.361 & 18.40 & 0.577 & 0.0485 & 18.88 & 0.999 \\
\hline GO15-MIL-101(Fe) & e) 0.179 & 36.93 & 0.961 & 0.0117 & 38.46 & 0.999 \\
\hline
\end{tabular}

The real uranium-contaminated water always had several coexisting ions which could interfere with the adsorption of uranium on the adsorbents. Therefore, the adsorption percentage of uranyl ions on MIL-101(Fe) and the composite was monitored to eValuate the effect of various cations and anions (Figure 5a,b). According to the statistics shown in Table S3, GO15-MIL-101(Fe) showed an overall improved adsorption performance in comparison with MIL-101-(Fe) under different coexisted anions and cations. Especially, the adsorption of U(VI) on the composite samples was less suppressed 
in the presence of $\mathrm{Ca}^{2+}$ and $\mathrm{CO}_{3}{ }^{2-}$, while that for MIL-101(Fe) was largely reduced. Several studies have eVidenced that in the presence of $\mathrm{Ca}^{2+}$ and dissolved $\mathrm{CO}_{3}{ }^{2-}$, the formation of $\mathrm{Ca}_{2} \mathrm{UO}_{2}\left(\mathrm{CO}_{3}\right)_{3}(\mathrm{aq})$ can decrease the adsorption of U(VI) on adsorbents [67]. eVen in aqueous solutions without $\mathrm{Ca}^{2+}$, the existence of $\mathrm{CO}_{3}{ }^{2-}$ with the concentration of $10 \mathrm{mM}$ can greatly influence the speciation of $\mathrm{U}(\mathrm{VI})$ [68]. $\left(\mathrm{UO}_{2} \mathrm{CO}_{3}(\mathrm{aq})\right)$ become dominant $\mathrm{U}(\mathrm{VI})$ species at $\mathrm{pH}=5.5$, leading to the decreased adsorption capacity. The slightly affected performance of GO15-MIL-101(Fe) indicated that the synergistic effect between GO and MIL-101(Fe) could greatly improve the capability of the adsorbents in resisting the interference of coexisted ions. The high retention of adsorption efficiency in simulated groundwater and surface water (Figure S4) indicated the potential of GO15-MIL-101(Fe) in uranium elimination from various wastewaters.
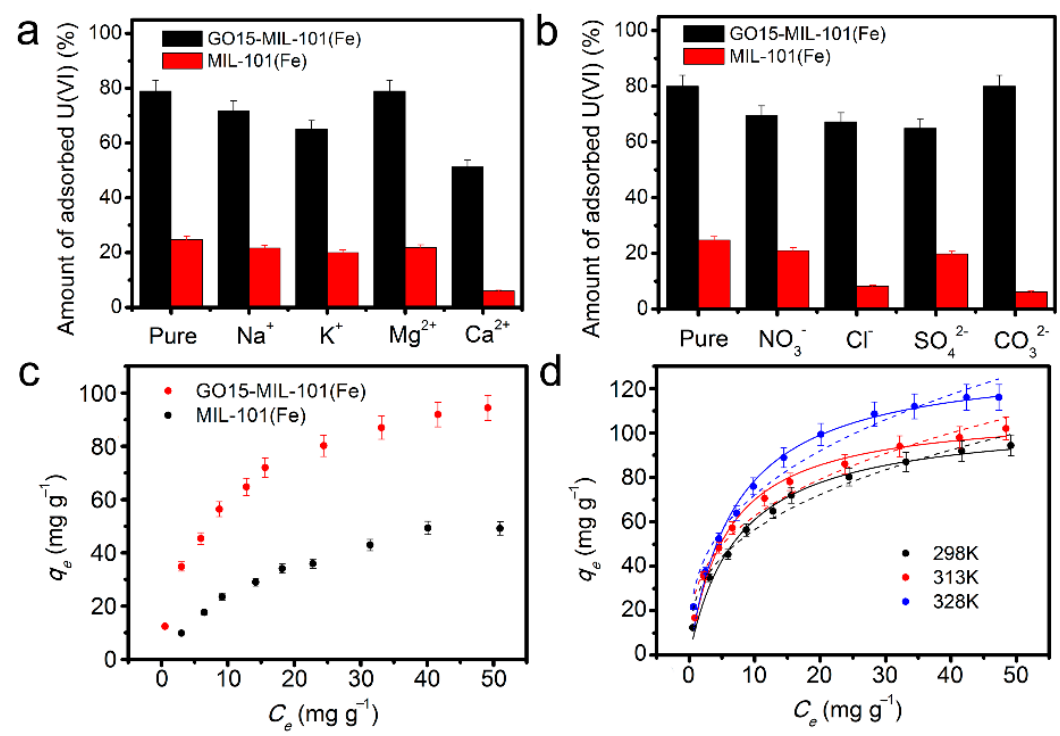

Figure 5. The effect of different (a) cation ions and (b) anion ions on the amount of adsorbed U (VI) on MIL-101(Fe) and GO15h-MIL-101(Fe) composites $\left(C_{0}=10 \mathrm{mg} \mathrm{L}^{-1}, \mathrm{pH}=5.5, \mathrm{~T}=298 \mathrm{~K}, \mathrm{~m} / \mathrm{V}=0.2 \mathrm{~g} \mathrm{~L}^{-1}\right.$, and $\left.\mathrm{I}_{\mathrm{NaNO}_{3}}=0.01 \mathrm{M}\right)$, (c) comparison of adsorption isotherms of MIL-101(Fe) and GO15-MIL-101(Fe) composites, and (d) adsorption isotherms of GO15-MIL-101(Fe) composite under different temperature $\left(\mathrm{T}=298 \mathrm{~K}, 313 \mathrm{~K}, 328 \mathrm{~K}, \mathrm{pH}=5.5, m / V=0.2 \mathrm{~g} \mathrm{~L}^{-1}\right.$, and $\left.\mathrm{I}_{\mathrm{NaNO}_{3}}=0.01 \mathrm{M}\right)$. The solid and dashed lines represent the Langmuir model and Freundlich model, respectively.

The maximum adsorption capacity of MIL-101(Fe) and composite samples were determined by plotting the adsorption isotherms $\left(q_{e}\right.$ vs. $\left.C_{e}\right)$ under $\mathrm{pH}=5.5$ and $\mathrm{T}=298 \mathrm{~K}$. Figure $5 \mathrm{c}$ indicated that with the increasing of equilibrium $\mathrm{U}(\mathrm{VI})$ concentration, the equilibrium adsorption capacity increased rapidly at first and then reached a saturated value. Obviously, the GO15-MIL-101(Fe) composite possessed much higher adsorption capacity than pure MIL-101(Fe). The adsorption isotherms were simulated through the Langmuir model (Equation (5)) and Freundlich model (Equation (6)). The Langmuir model describes monolayer adsorption onto the homogeneous surface with equivalent active sites. In contrast, the Freundlich model refers to multilayer adsorption on a surface with a heterogeneous surface.

$$
\begin{aligned}
& q_{e}=\frac{b q_{\max } C_{e}}{1+b C_{e}} \\
& q_{e}=K_{F} C_{e}^{1 / n_{F}}
\end{aligned}
$$

where $q_{\max }$ refers to the maximum adsorption capacity, $b$ is the Langmuir constant $\left(\mathrm{L} \mathrm{mg}^{-1}\right)$, $K_{F}$ and $n_{F}$ represent the Freundlich constants corresponding to the capacity and intensity of adsorption, respectively. As listed in Table 2, the calculated $q_{\max }$ was $106.89 \mathrm{mg} \mathrm{g}^{-1}$ for the GO15-MIL-101(Fe) composite, which was much larger than that of MIL-101(Fe) (68.93 $\mathrm{mg} \mathrm{g}^{-1}$ ), respectively. The larger value of $R^{2}$ indicated that the Langmuir model fitted the adsorption 
isotherms of both the GO15-MIL-101(Fe) composite and MIL-101(Fe) better than the Freundlich model. This analysis confirmed the monolayer adsorption nature of the U(VI) adsorption on the samples. As summarized in Table S3, the GO15-MIL-101(Fe) composite an exhibited competitive adsorption capacity achieved from the facile one-pot synthetic process in comparison with other adsorbents.

Table 2. The simulated adsorption isotherm parameters of U(VI) on MIL-101(Fe) and GO15-MIL-101(Fe) composites at $298 \mathrm{~K}$.

\begin{tabular}{lcccccc}
\hline \multirow{2}{*}{$\mathbf{T}(\mathbf{K})$} & \multicolumn{3}{c}{ Langmuir } & \multicolumn{3}{c}{ Freundlich } \\
\cline { 2 - 7 } & $\boldsymbol{q}_{\max }\left(\mathbf{m g ~ g}^{-\mathbf{1}}\right)$ & $\boldsymbol{b}\left(\mathbf{L ~ m g}^{-\mathbf{1}}\right)$ & $\boldsymbol{R}^{\mathbf{2}}$ & $\boldsymbol{K}_{\boldsymbol{F}}\left(\mathbf{m o l}^{\mathbf{1 - n}} \mathbf{L}^{\mathbf{n}} \mathbf{~ g}^{-\mathbf{1}}\right)$ & $\boldsymbol{n}$ & $\boldsymbol{R}^{\mathbf{2}}$ \\
\hline MIL-101(Fe) & 68.93 & 0.053 & 0.991 & 7.66 & 2.03 & 0.969 \\
GO15-MIL-101(Fe) & 106.89 & 0.132 & 0.989 & 24.96 & 2.824 & 0.973 \\
\hline
\end{tabular}

As shown in Figure 5d, the thermodynamics of U(VI) adsorption on the GO15-MIL-101(Fe) composite was studied based on the adsorption isotherms at different temperatures. The fitted parameters based on Equations (5) and (6) are listed in Table 3. Clearly, $q_{\max }$ became larger with temperature, indicating that the adsorption of uranyl ions on GO15-MIL-101(Fe) was endothermic [69]. To eValuate how temperature affects the adsorption process, the thermodynamic parameters including the Gibbs free energy change $\left(\Delta G^{0}\right)$, the enthalpy change $\left(\Delta H^{0}\right)$, and the entropy change $\left(\Delta S^{0}\right)$ were achieved from the following equations:

$$
\begin{aligned}
\Delta G^{0} & =-R T \ln K^{0} \\
\ln K^{0} & =\frac{\Delta S^{0}}{R}-\frac{\Delta H^{0}}{R T}
\end{aligned}
$$

Firstly, $K^{0}$, the equilibrium constant, was obtained from plots of $\ln K_{d}$ as a function of $C_{e}$ while extrapolating $C_{e}$ to zero $\left(K_{d}=\frac{C_{0}-C_{e}}{C_{e}} \times \frac{V}{m}\right)$ based on the experimental data. $\Delta G^{0}$ under different temperatures can be further achieved from Equation (7). Figure S5 showed a good linear relationship between $\ln K^{0}$ and 1/T for GO15-MIL-101(Fe). The slope and intercept corresponded to $\Delta H^{0}(\mathrm{~kJ}$ $\left.\mathrm{mol}^{-1}\right)$ and $\Delta S^{0}\left(\mathrm{~J} \mathrm{~mol}^{-1} \mathrm{~K}^{-1}\right)$ of the adsorption, respectively. The negative $\Delta G^{0}$ and its increased absolute value, as well as the positive $\Delta H^{0}$, illustrated that the uptake of U(VI) by GO15-MIL-101(Fe) was spontaneous and endothermic (Table 4). This result manifested that the adsorbed heat for U(VI) dehydration was larger than the energy which was released from the process of uranyl ions binding on the surface of the adsorbents. The positive $\Delta S^{0}\left(104.34 \mathrm{~J} \mathrm{~mol}^{-1} \mathrm{~K}^{-1}\right)$ and very negative $\Delta G^{0}$ indicated the strong interaction between the GO15-MIL-101(Fe) and U(VI).

\begin{tabular}{|c|c|c|c|c|c|c|}
\hline \multirow{2}{*}{$\mathrm{T}(\mathrm{K})$} & \multicolumn{3}{|c|}{ Langmuir } & \multicolumn{3}{|c|}{ Freundlich } \\
\hline & $q_{\max }\left(\mathrm{mg} \mathrm{g}^{-1}\right)$ & $b\left(\mathrm{~L} \mathrm{mg}^{-1}\right)$ & $R^{2}$ & $K_{F}\left(\mathrm{~mol}^{1-n} \mathrm{~L}^{\mathrm{n}} \mathrm{g}^{-1}\right)$ & n & $R^{2}$ \\
\hline 298 & 106.89 & 0.13 & 0.989 & 24.97 & 2.82 & 0.973 \\
\hline 313 & 110.15 & 0.17 & 0.988 & 28.85 & 2.96 & 0.901 \\
\hline 328 & 133.83 & 0.14 & 0.986 & 32.20 & 2.85 & 0.929 \\
\hline
\end{tabular}

Table 3. The simulated adsorption isotherm parameters of U(VI) on GO15-MIL-101(Fe) composite.

\begin{tabular}{|c|c|c|c|c|c|}
\hline \multirow{2}{*}{ Adsorbents } & \multicolumn{3}{|c|}{$\Delta G^{0}\left(\mathrm{~kJ} \mathrm{~mol}{ }^{-1}\right)$} & \multirow{2}{*}{$\Delta H^{0}\left(\mathrm{~kJ} \mathrm{~mol}^{-1}\right)$} & \multirow{2}{*}{$\Delta S^{0}\left(\mathrm{~J} \mathrm{~mol}^{-1} \mathrm{~K}^{-1}\right)$} \\
\hline & $298 \mathrm{~K}$ & $313 \mathrm{~K}$ & $328 \mathrm{~K}$ & & \\
\hline GO15-MIL-101(Fe) & -23.16 & -24.71 & -26.29 & 7.96 & 104.34 \\
\hline
\end{tabular}

Table 4. The thermodynamic parameters for U(VI) adsorption on and the GO15-MIL-101(Fe) composite.

The application potential of GO15-MIL-101(Fe) was investigated through several cycles of regeneration and reusing experiments. The low adsorption efficiency of GO15-MIL-101(Fe) under $\mathrm{pH}<3$ indicated that $\mathrm{U}(\mathrm{VI})$ ions may desorb from adsorbents by decreasing the solution $\mathrm{pH}$. 
Therefore, nitric acid was used to desorb the uranyl ions in the regeneration experiment. As shown in Figure 6, GO15-MIL-101(Fe) showed the negligible reduction of adsorption efficiency in the first two reabsorption process. The adsorption decay became obvious after 4 cycles but gradually became steady in further tests. The performance decrease may arise from the incomplete desorption of uranyl ions and the partial aggregation of the composite sample (Figure S7). Because of the growth of MIL-101(Fe) on the surface, the aggregation did not deteriorate further, giving rise to the gradually steady reusing performance. After 8 cycles the samples still maintained $~ 75 \%$ of the original adsorption efficiency. The results implied that GO15-MIL-101(Fe) was a promising composite adsorbent with a good reusability.

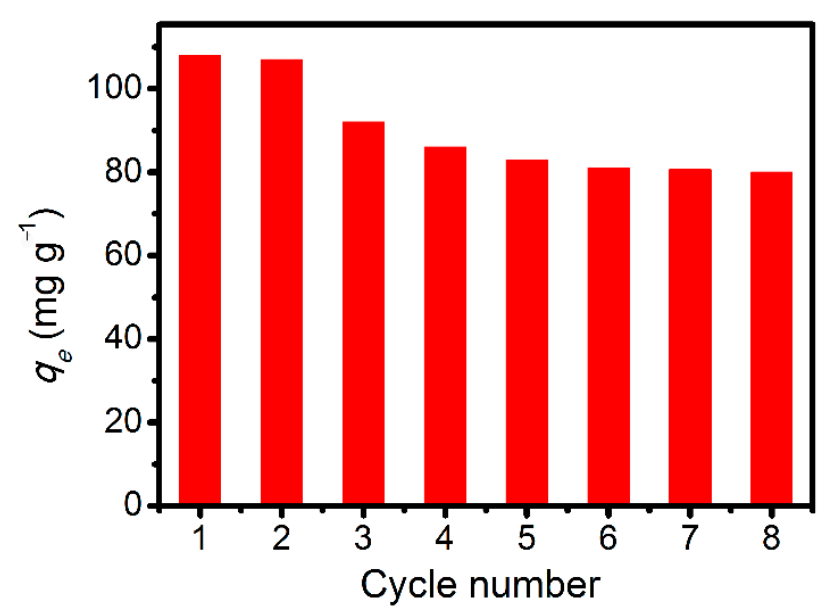

Figure 6. The recycling performance of GO15-MIL-101(Fe) in the removal of U(VI) from aqueous solution $\left(C_{0}=10 \mathrm{mg} \mathrm{L}^{-1}, \mathrm{pH}=5.5, \mathrm{~T}=298 \mathrm{~K}, m / V=0.2 \mathrm{~g} \mathrm{~L}^{-1}\right.$, and $\left.\mathrm{I}_{\mathrm{NaNO}_{3}}=0.01 \mathrm{M}\right)$.

\section{Conclusions}

To conclude, the GO-MIL-101(Fe) sandwich composite was synthesized through a facile in situ growth method. By changing the amount of GO precursors, the size and distribution density of MIL-101(Fe) in the composites were easily tuned. Notably, batch adsorption experiments showed that GO-15-MIL-101(Fe) possessed superior adsorption performance with enhanced adsorption efficiency and improved adsorption capacity $\left(106.89 \mathrm{mg} \mathrm{g}^{-1}\right.$ at $\left.\mathrm{pH}=5.5, \mathrm{~T}=298 \mathrm{~K}\right)$ compared with raw MIL-101(Fe) (68.93 $\mathrm{mg} \mathrm{g}^{-1}$ at same condition). The uptake of U(VI) by GO15-MIL-101(Fe) was realized through the inner-sphere surface complexation as well as electrostatic interaction. FT-IR and XPS analysis illustrated the importance of the synergistic effect between GO nanosheets and MIL-101(Fe) octahedrons on the resultant adsorption performance. Moreover, the good reusing capability of GO15-MIL-101(Fe) indicated the application potential of such a composite material. Therefore, this work provided an effective route to design advanced composite adsorbents with satisfying radionuclide uptake ability by giving play to the functionality of individual components.

Supplementary Materials: The following are available online at http:/ /www.mdpi.com/2076-3417/8/11/2270/s1, Table S1: Composition of groundwater and surface water used to eValuate the adsorption of U(VI) on GO15-MIL-101(Fe), Figure S1: XRD pattern of as-prepared MIL-101(Fe) and GO-MIL-101(Fe) composite, Figure S2: Nitrogen adsorption-desorption isotherm and pore size distribution of (a) and (b) MIL-101(Fe), (c) and (d) GO15-MIL-101(Fe), Table S2: Summary of surface area and pore volume obtained from $\mathrm{N}_{2}$ adsorption isotherms, Figure S3: The adsorption efficiency of GO15-MIL-101(Fe) towards U(VI) at different initial U(VI) concentrations $\left(0.035 \mathrm{mg} \mathrm{L}^{-1}, 1.3 \mathrm{mg} \mathrm{L}^{-1}, 3 \mathrm{mg} \mathrm{L}^{-1}\right.$ and $\left.10 \mathrm{mg} \mathrm{L}^{-1}\right)$. The inset numbers represent the adsorbent dosage, Figure S4: U(VI) speciation based on Visual MINTEQ program in the experimental adsorption solution $\left([\mathrm{U}(\mathrm{VI})]=10 \mathrm{mg} \mathrm{L}^{-1}, \mathrm{I}=0.01 \mathrm{~mol} \mathrm{~L}^{-1}\left(\mathrm{NaNO}_{3}\right)\right.$, and $\left.\mathrm{T}=25^{\circ} \mathrm{C}\right)$, Table S3. Comparison of the adsorption efficiency of GO15-MIL-101(Fe) and MIL-101(Fe) under different coexisted ions with that in the absence of these ions, Figure S5: The adsorption efficiency of GO15-MIL-101(Fe) towards U(VI) in deionized water $(\mathrm{pH}=5.5)$, simulated surface water $(\mathrm{pH}=7.9)$ and simulated groundwater $(\mathrm{pH}=8.0)$ at $\mathrm{T}=298 \mathrm{~K}$, and $\mathrm{C}_{0}=10 \mathrm{mg} \mathrm{L}^{-1}$, adsorbent concentration $=0.2 \mathrm{~g} \mathrm{~L}^{-1}$, Table S4: Comparison of the adsorption capacity of GO-MIL-101(Fe) composite towards U(VI) with other adsorbents, Figure S6: The plot of $\operatorname{lnK}_{0}$ to $1 / \mathrm{T}$ of U(VI) 
adsorption onto GO15-MIL-101(Fe). Figure S7: The morphology of regenerated composite sample after 4 cycles, scale bar $=1 \mu \mathrm{m}$.

Author Contributions: B.H. conceived the project. B.H. conducted the experiment and performed the measurements with help from E.Z. and G.C. Data analysis were carried out by B.H. and E.Z. All the authors discussed the results and commented on the manuscript.

Funding: This research was funded by the National Natural Science Foundation of China (21703064) and the Fundamental Research Funds for the Central Universities (2017MS046).

Acknowledgments: The authors wish to thank the National Natural Science Foundation of China and Ministry of Education of the People's Republic of China for the funding support.

Conflicts of Interest: The authors declare no conflict of interest.

\section{References}

1. Domingo, J.L. Reproductive and developmental toxicity of natural and depleted uranium: A review. Reprod. Toxicol. 2001, 15, 603-609. [CrossRef]

2. Holdway, D.A. Uranium toxicity to two species of Australian tropical fish. Sci. Total Environ. 1992, 125, 137-158. [CrossRef]

3. Cheng, K.L.; Hogan, A.C.; Parry, D.L.; Markich, S.J.; Harford, A.J.; van Dam, R.A. Uranium toxicity and speciation during chronic exposure to the tropical freshwater fish, mogurnda mogurnda. Chemosphere 2010, 79, 547-554. [CrossRef] [PubMed]

4. Tian, G.; Geng, J.X.; Jin, Y.D.; Wang, C.L.; Li, S.Q.; Chen, Z.; Wang, H.; Zhao, Y.S.; Li, S.J. Sorption of uranium(VI) using oxime-grafted ordered mesoporous carbon cmk-5. J. Hazard. Mater. 2011, 190, 442-450. [CrossRef] [PubMed]

5. Kumar, J.R.; Kim, J.-S.; Lee, J.-Y.; Yoon, H.-S. A brief review on solvent extraction of uranium from acidic solutions. Sep. Purif. Rev. 2011, 40,77-125. [CrossRef]

6. Manos, M.J.; Kanatzidis, M.G. Layered metal sulfides capture uranium from seawater. J. Am. Chem. Soc. 2012, 134, 16441-16446. [CrossRef] [PubMed]

7. Abney, C.W.; Mayes, R.T.; Saito, T.; Dai, S. Materials for the recovery of uranium from seawater. Chem. Rev. 2017, 117, 13935-14013. [CrossRef] [PubMed]

8. Li, Z.; Chen, F.; Yuan, L.; Liu, Y.; Zhao, Y.; Chai, Z.; Shi, W. Uranium(VI) adsorption on graphene oxide nanosheets from aqueous solutions. Chem. Eng. J. 2012, 210, 539-546. [CrossRef]

9. Hua, Y.; Wang, W.; Huang, X.; Gu, T.; Ding, D.; Ling, L.; Zhang, W.-X. Effect of bicarbonate on aging and reactivity of nanoscale zerovalent iron (nZVI) toward uranium removal. Chemosphere 2018, 201, 603-611. [CrossRef] [PubMed]

10. Shao, L.; Wang, X.; Ren, Y.; Wang, S.; Zhong, J.; Chu, M.; Tang, H.; Luo, L.; Xie, D. Facile fabrication of magnetic cucurbit [6]uril/graphene oxide composite and application for uranium removal. Chem. Eng. J. 2016, 286, 311-319. [CrossRef]

11. Sun, Y.; Ding, C.; Cheng, W.; Wang, X. Simultaneous adsorption and reduction of U(VI) on reduced graphene oxide-supported nanoscale zerovalent iron. J. Hazard. Mater. 2014, 280, 399-408. [CrossRef] [PubMed]

12. Rizescu, C.; Podolean, I.; Albero, J.; Parvulescu, V.I.; Coman, S.M.; Bucur, C.; Puche, M.; Garcia, H. N-doped graphene as a metal-free catalyst for glucose oxidation to succinic acid. Green Chem. 2017, 19, 1999-2005. [CrossRef]

13. Fei, F.; Cseri, L.; Szekely, G.; Blanford, C.F. Robust covalently cross-linked polybenzimidazole/graphene oxide membranes for high-flux organic solvent nanofiltration. ACS Appl. Mater. Interfaces 2018, 10, 16140-16147. [CrossRef] [PubMed]

14. Tan, L.; Liu, Q.; Jing, X.; Liu, J.; Song, D.; Hu, S.; Liu, L.; Wang, J. Removal of uranium(VI) ions from aqueous solution by magnetic cobalt ferrite/multiwalled carbon nanotubes composites. Chem. Eng. J. 2015, 273, 307-315. [CrossRef]

15. Fasfous, I.I.; Dawoud, J.N. Uranium (VI) sorption by multiwalled carbon nanotubes from aqueous solution. Appl. Surf. Sci. 2012, 259, 433-440. [CrossRef]

16. Luo, H.; Liu, Z.; Chao, L.; Wu, X.; Lei, X.; Chang, Z.; Sun, X. Adsorption and desorption of U(VI) on functionalized graphene oxides: A combined experimental and theoretical study. Environ. Sci. Technol. 2015, 3, 3667-3675. 
17. Han, B.; Zhang, E.; Cheng, G.; Zhang, L.; Wang, D.; Wang, X. Hydrothermal carbon superstructures enriched with carboxyl groups for highly efficient uranium removal. Chem. Eng. J. 2018, 338, 734-744. [CrossRef]

18. Lv, M.; Yan, L.; Liu, C.; Su, C.; Zhou, Q.; Zhang, X.; Lan, Y.; Zheng, Y.; Lai, L.; Liu, X.; et al. Non-covalent functionalized graphene oxide (GO) adsorbent with an organic gelator for co-adsorption of dye, endocrine-disruptor, pharmaceutical and metal ion. Chem. Eng. J. 2018, 349, 791-799. [CrossRef]

19. Schierz, A.; Zänker, H. Aqueous suspensions of carbon nanotubes: Surface oxidation, colloidal stability and uranium sorption. Environ. Pollut. 2009, 157, 1088-1094. [CrossRef] [PubMed]

20. Sun, Y.B.; Shao, D.D.; Chen, C.; Yang, S.B.; Wang, X.K. Highly efficient enrichment of radionuclides on graphene oxide-supported polyaniline. Environ. Sci. Technol. 2013, 47, 9904-9910. [CrossRef] [PubMed]

21. Tan, L.; Wang, Y.; Liu, Q.; Wang, J.; Jing, X.; Liu, L.; Liu, J.; Song, D. Enhanced adsorption of uranium (VI) using a three-dimensional layered double hydroxide/graphene hybrid material. Chem. Eng. J. 2015, 259, 752-760. [CrossRef]

22. Li, Z.-J.; Wang, L.; Yuan, L.-Y.; Xiao, C.-L.; Mei, L.; Zheng, L.-R.; Zhang, J.; Yang, J.-H.; Zhao, Y.-L.; Zhu, Z.-T.; et al. Efficient removal of uranium from aqueous solution by zero-valent iron nanoparticle and its graphene composite. J. Hazard. Mater. 2015, 290, 26-33. [CrossRef] [PubMed]

23. El-Maghrabi, H.H.; Abdelmaged, S.M.; Nada, A.A.; Zahran, F.; El-Wahab, S.A.; Yahea, D.; Hussein, G.M.; Atrees, M.S. Magnetic graphene based nanocomposite for uranium scavenging. J. Hazard. Mater. 2017, 322, 370-379. [CrossRef] [PubMed]

24. Song, W.; Wang, X.; Wang, Q.; Shao, D.; Wang, X. Plasma-induced grafting of polyacrylamide on graphene oxide nanosheets for simultaneous removal of radionuclides. Phys. Chem. Chem. Phys. 2015, 17, 398-406. [CrossRef] [PubMed]

25. Hu, R.; Shao, D.; Wang, X. Graphene oxide/polypyrrole composites for highly selective enrichment of U(VI) from aqueous solutions. Polym. Chem. 2014, 5, 6207-6215. [CrossRef]

26. Linghu, W.; Yang, H.; Sun, Y.; Sheng, G.; Huang, Y. One-pot synthesis of LDH/GO composites as highly effective adsorbents for decontamination of U(VI). ACS Sustain. Chem. Eng. 2017, 5, 5608-5616. [CrossRef]

27. Li, J.-R.; Kuppler, R.J.; Zhou, H.-C. Selective gas adsorption and separation in metal-organic frameworks. Chem. Soc. Rev. 2009, 38, 1477-1504. [CrossRef] [PubMed]

28. Chen, H.; Shen, K.; Mao, Q.; Chen, J.; Li, Y. Nanoreactor of MOF-derived yolk-shell Co@C-N: Precisely controllable structure and enhanced catalytic activity. ACS Catal. 2018, 8, 1417-1426. [CrossRef]

29. Towsif Abtab, S.M.; Alezi, D.; Bhatt, P.M.; Shkurenko, A.; Belmabkhout, Y.; Aggarwal, H.; Weseliński, Ł.J.; Alsadun, N.; Samin, U.; Hedhili, M.N.; et al. Reticular chemistry in action: A hydrolytically stable MOF capturing twice its weight in adsorbed water. Chem 2018, 4, 94-105. [CrossRef]

30. Tan, L.; Wang, Y.; Liu, Q.; Wang, J.; Jing, X.; Liu, L.; Liu, J.; Song, D. Superior removal of arsenic from water with zirconium metal-organic framework UiO-66. Sci. Rep. 2015, 259, 752-760.

31. Ma, S.L.; Huang, L.; Ma, L.J.; Shim, Y.; Islam, S.M.; Wang, P.L.; Zhao, L.D.; Wang, S.C.; Sun, G.B.; Yang, X.J.; et al. Functionalized metal-organic framework as a new platform for efficient and selective removal of cadmium (II) from aqueous solution. J. Mater. Chem. A 2015, 137, 3670-3677.

32. Karmakar, S.; Dechnik, J.; Janiak, C.; De, S. Aluminium fumarate metal-organic framework: A super adsorbent for fluoride from water. J. Hazard. Mater. 2016, 303, 10-20. [CrossRef] [PubMed]

33. Campbell, J.; Burgal, J.D.S.; Szekely, G.; Davies, R.P.; Braddock, D.C.; Livingston, A. Hybrid polymer/MOF membranes for organic solvent nanofiltration (OSN): Chemical modification and the quest for perfection. J. Membr. Sci. 2016, 503, 166-176. [CrossRef]

34. Carboni, M.; Abney, C.W.; Liu, S.; Lin, W. Highly porous and stable metal-organic frameworks for uranium extraction. Chem. Sci. 2013, 4, 2396-2402. [CrossRef]

35. Kumar, P.; Pournara, A.; Kim, K.-H.; Bansal, V.; Rapti, S.; Manos, M.J. Metal-organic frameworks: Challenges and opportunities for ion-exchange/sorption applications. Prog. Mater. Sci. 2017, 86, 25-74. [CrossRef]

36. Li, L.N.; Ma, W.; Shen, S.S.; Huang, H.X.; Bai, Y.; Liu, H.W. A combined experimental and theoretical study on the extraction of uranium by amino-derived metal-organic frameworks through post-synthetic strategy. ACS Appl. Mater. Interfaces 2016, 8, 31032-31041. [CrossRef] [PubMed]

37. De Decker, J.; Folens, K.; De Clercq, J.; Meledina, M.; Van Tendeloo, G.; Du Laing, G.; Van Der Voort, P. Ship-in-a-bottle CMPO in MIL-101(Cr) for selective uranium recovery from aqueous streams through adsorption. J. Hazard. Mater. 2017, 335, 1-9. [CrossRef] [PubMed] 
38. De Decker, J.; Rochette, J.; De Clercq, J.; Florek, J.; Van Der Voort, P. Carbamoylmethylphosphine oxide-functionalized MIL-101(Cr) as highly selective uranium adsorbent. Anal. Chem. 2017, 89, 5678-5682. [CrossRef] [PubMed]

39. Yang, P.; Liu, Q.; Liu, J.; Zhang, H.; Li, Z.; Li, R.; Liu, L.; Wang, J. Interfacial growth of a metal-organic framework (UiO-66) on functionalized graphene oxide (GO) as a suitable seawater adsorbent for extraction of uranium(VI). J. Mater. Chem. A 2017, 5, 17933-17942. [CrossRef]

40. Bai, Z.Q.; Yuan, L.Y.; Zhu, L.; Liu, Z.R.; Chu, S.Q.; Zheng, L.R.; Zhang, J.; Chai, Z.F.; Shi, W.Q. Introduction of amino groups into acid-resistant MOFs for enhanced U(VI) sorption. J. Mater. Chem. A 2015, 3, 525-534. [CrossRef]

41. Jabbari, V.; Veleta, J.M.; Zarei-Chaleshtori, M.; Gardea-Torresdey, J.; Villagrán, D. Green synthesis of magnetic MOF@GO and MOF@CNT hybrid nanocomposites with high adsorption capacity towards organic pollutants. Chem. Eng. J. 2016, 304, 774-783. [CrossRef]

42. Petit, C.; Bandosz, T.J. MOF-graphite oxide nanocomposites: Surface characterization and eValuation as adsorbents of ammonia. J. Mater. Chem. 2009, 19, 6521-6528. [CrossRef]

43. Hummers, W.S.; Offeman, R.E. Preparation of graphitic oxide. J. Am. Chem. Soc. 1958, 80, 1339. [CrossRef]

44. Karel, F.; Karen, L.; Ricci, N.N.; Maria, M.; Stuart, T.; Gustaaf, V.T.; Du, L.G.; Pascal, V.D.V. $\mathrm{Fe}_{3} \mathrm{O}_{4} @ \mathrm{MIL}-101-\mathrm{A}$ selective and regenerable adsorbent for the removal of as species from water. Eur. J. Inorg. Chem. 2016, 2016, 4395-4401.

45. Jiang, D.; Burrows, A.D.; Edler, K.J. Size-controlled synthesis of MIL-101(Cr) nanoparticles with enhanced selectivity for $\mathrm{CO}_{2}$ over $\mathrm{N}_{2}$. CrystEngComm 2011, 13, 6916-6919. [CrossRef]

46. Konkena, B.; Vasudevan, S. Understanding aqueous dispersibility of graphene oxide and reduced graphene oxide through pKa measurements. J. Phys. Chem. Lett. 2012, 3, 867-872. [CrossRef] [PubMed]

47. Zhou, X.; Huang, W.; Shi, J.; Zhao, Z.; Xia, Q.; Li, Y.; Wang, H.; Li, Z. A novel mof/graphene oxide composite GrO@MIL-101 with high adsorption capacity for acetone. J. Mater. Chem. A 2014, 2, 4722-4730. [CrossRef]

48. Saikia, M.; Saikia, L. Sulfonic acid-functionalized MIL-101(Cr) as a highly efficient heterogeneous catalyst for one-pot synthesis of 2-amino-4H-chromenes in aqueous medium. RSC Adv. 2016, 6, 15846-15853. [CrossRef]

49. Gao, L.; Li, C.-Y.V.; Yung, H.; Chan, K.-Y. A functionalized MIL-101(Cr) metal-organic framework for enhanced hydrogen release from ammonia borane at low temperature. Chem. Commun. 2013, 49, 10629-10631. [CrossRef] [PubMed]

50. Sun, X.; Xia, Q.; Zhao, Z.; Li, Y.; Li, Z. Synthesis and adsorption performance of MIL-101(Cr)/graphite oxide composites with high capacities of n-hexane. Chem. Eng. J. 2014, 239, 226-232. [CrossRef]

51. Li, X.; Guo, W.; Liu, Z.; Wang, R.; Liu, H. Quinone-modified $\mathrm{NH}_{2}-\mathrm{MIL}-101(\mathrm{Fe})$ composite as a redox mediator for improved degradation of bisphenol A. J. Hazard. Mater. 2017, 324, 665-672. [CrossRef] [PubMed]

52. Liu, Q.; Ning, L.; Zheng, S.; Tao, M.; Shi, Y.; He, Y. Adsorption of carbon dioxide by MIL-101(Cr): Regeneration conditions and influence of flue gas contaminants. Sci. Rep. 2013, 3, 2916. [CrossRef] [PubMed]

53. Zhang, S.; Shu, X.; Zhou, Y.; Huang, L.; Hua, D. Highly efficient removal of uranium (VI) from aqueous solutions using poly(acrylic acid)-functionalized microspheres. Chem. Eng. J. 2014, 253, 55-62. [CrossRef]

54. Yang, S.-T.; Chen, S.; Chang, Y.; Cao, A.; Liu, Y.; Wang, H. Removal of methylene blue from aqueous solution by graphene oxide. J. Colloid Interface Sci. 2011, 359, 24-29. [CrossRef] [PubMed]

55. Wager, C.D.; Riggs, W.H.; Davis, L.E.; Moulder, J.F.; Meilenberg, G.E. Handbook of X-ray Photoelectron Spectroscopy; Perkin-Elmer Coorperation: Eden Prairie, MN, USA, 1979.

56. VG Scientific Auger Handbook; VG Scientific Limited: West Sussex, UK, 1989.

57. Makarova, L.G.; Shabanova, I.N.; Kodolov, V.I.; Besogonov, Y.V. X-ray photoelectron spectroscopy as a method to control the received metal-carbon nanostructures. J. Electron Spectrosc. Relat. Phenom. 2004, 137-140, 239-242. [CrossRef]

58. Lu, H.B.; Campbell, C.T.; Graham, D.J.; Ratner, B.D. Surface characterization of hydroxyapatite and related calcium phosphates by XPS and tof-sims. Anal. Chem. 2000, 72, 2886-2894. [CrossRef] [PubMed]

59. Dhankhar, S.; Bhalerao, G.; Ganesamoorthy, S.; Baskar, K.; Singh, S. Growth and comparison of single crystals and polycrystalline brownmillerite $\mathrm{Ca}_{2} \mathrm{Fe}_{2} \mathrm{O}_{5}$. J. Cryst. Growth 2017, 468, 311-315. [CrossRef]

60. Terzyk, A.P. The influence of activated carbon surface chemical composition on the adsorption of acetaminophen (paracetamol) in vitro: Part II. TG, FTIR, and XPS analysis of carbons and the temperature dependence of adsorption kinetics at the neutral pH. Colloids Surf. A 2001, 177, 23-45. [CrossRef] 
61. Liu, Q.; Guo, B.; Rao, Z.; Zhang, B.; Gong, J.R. Strong two-photon-induced fluorescence from photostable, biocompatible nitrogen-doped graphene quantum dots for cellular and deep-tissue imaging. Nano Lett. 2013, 13, 2436-2441. [CrossRef] [PubMed]

62. Han, B.; Cheng, G.; Zhang, E.; Zhang, L.; Wang, X. Three dimensional hierarchically porous ZIF-8 derived carbon/LDH core-shell composite for high performance supercapacitors. Electrochim. Acta 2018, 263, 391-399. [CrossRef]

63. Seredych, M.; Petit, C.; Tamashausky, A.V.; Bandosz, T.J. Role of graphite precursor in the performance of graphite oxides as ammonia adsorbents. Carbon 2009, 47, 445-456. [CrossRef]

64. Hayes, K.F.; Papelis, C.; Leckie, J.O. Modeling ionic strength effects on anion adsorption at hydrous oxide/solution interfaces. J. Colloid Interface Sci. 1988, 125, 717-726. [CrossRef]

65. Azizian, S. Kinetic models of sorption: A theoretical analysis. J. Colloid Interface Sci. 2004, 276, 47-52. [CrossRef] [PubMed]

66. Miyake, Y.; Ishida, H.; Tanaka, S.; Kolev, S.D. Theoretical analysis of the pseudo-second order kinetic model of adsorption. Application to the adsorption of $\mathrm{Ag}(\mathrm{I})$ to mesoporous silica microspheres functionalized with thiol groups. Chem. Eng. J. 2013, 218, 350-357. [CrossRef]

67. Dong, W.; Ball, W.P.; Liu, C.; Wang, Z.; Stone, A.T.; Bai, J.; Zachara, J.M. Influence of calcite and dissolved calcium on uranium(VI) sorption to a hanford subsurface sediment. Environ. Sci. Technol. 2005, 39, 7949-7955. [CrossRef] [PubMed]

68. Wen, T.; Wang, X.; Wang, J.; Chen, Z.; Li, J.; Hu, J.; Hayat, T.; Alsaedi, A.; Grambow, B.; Wang, X. A strategically designed porous magnetic $\mathrm{N}$-doped $\mathrm{Fe} / \mathrm{Fe}_{3} \mathrm{C} @ \mathrm{C}$ matrix and its highly efficient uranium(VI) remediation. Inorg. Chem. Front. 2016, 3, 1227-1235. [CrossRef]

69. Ding, M.; Shi, W.; Guo, L.; Leong, Z.Y.; Baji, A.; Yang, H.Y. Rational design and synthesis of monodispersed hierarchical $\mathrm{SiO}_{2} @$ layered double hydroxide nanocomposites for efficient removal of pollutants from aqueous solution. Chem. Eng. J. 2017, 5, 6113-6121.

(C) 2018 by the authors. Licensee MDPI, Basel, Switzerland. This article is an open access article distributed under the terms and conditions of the Creative Commons Attribution (CC BY) license (http:/ / creativecommons.org/licenses/by/4.0/). 